\title{
KINERJA PELAYANAN PUBLIK DI KANTOR CAMAT DUMAI TIMUR
}

\section{Public Service Performance In Dumai Timur District office}

\section{Erinaldi}

Program Studi Ilmu Administrasi Negara, STIA Lancang Kuning

Dumai, Riau, Indonesia

Email:

erinaldipratama2905@gmail.com

Kata Kunci:

Kinerja

Publik

Pelayanan Publik

\section{Keywords: \\ Performance \\ Public}

Public Service

\author{
Accepted \\ Februari 2021 \\ Published \\ April 2021
}

\begin{abstract}
Abstrak
Peran utama pemerintah terhadap masyarakat adalah memberikan pelayanan guna memenuhi kebutuhan yang diinginkan masyarakat. Begitu pula dengan Kantor Camat Dumai Timur, dituntut untuk memberikan pelayanan yang berkualitas bagi masyarakat. Untuk memenuhi kebutuhan tersebut diperlukan kinerja pegawai yang baik dan terampil dalam mendukung percepatan pelayanan. Dalam pelaksanaannya, masih terdapat keluhan dari sebagian orang tentang prosedur yang berbelit-belit, tidak adanya kepastian waktu dinas, dan petugas yang kurang tanggap.

Tujuan penelitian ini adalah untuk mengetahui faktor-faktor yang mempengaruhi kinerja pelayanan pada Kantor Camat Dumai Timur. Teori yang digunakan dalam penelitian ini adalah teori (Ratminto \& Winarsih, 2013) yang menyatakan ada (I3) faktor yang mempengaruhi kinerja pelayanan yaitu strategi pelayanan, petugas / petugas berorientasi klien, sistem pelayanan berorientasi klien, komitmen manajemen, formulasi. tujuan organisasi, standarisasi tugas, kekompakan tim, kesesuaian orang-pekerjaan, kesesuaian teknologi-pekerjaan, realitas kontrol, kejelasan peran, konflik peran, tingkat manajemen. Responden dalam penelitian ini sebanyak 29 karyawan dengan teknik pengambilan sampel sensus. Analisis data menggunakan statistik deskriptif dengan skala pengukuran Skala Rating. Hasil penelitian mengenai faktor-faktor yang mempengaruhi kinerja pelayanan pada Kantor Camat Dumai Timur dikategorikan cukup baik dengan rata-rata sebesar $2236(65,90 \%)$.
\end{abstract}

\begin{abstract}
The main role of the government towards the people is to provide services in order to meet the needs desired by the community. Likewise, Dumai Timur District office is demanded to provide quality services for the community. To meet these needs requires good and skilled employee performance in supporting the acceleration of service. In its implementation, there are still complaints from some people about convoluted procedures, the absence of certainty in-service time, and less responsive officers.

The purpose of this study was to determine the factors that affect service performance at Dumai Timur District office. The theory used in this research is the theory (Ratminto \& Winarsih, 20/3)which states there are (I3) factors that influence service performance, namely service strategies, client-oriented officers/officers, client-oriented service systems, management commitment, formulation of organizational goals, standardization of tasks, team cohesiveness, person-job suitability, technology-job suitability, control reality, role clarity, role conflict, management level. Respondents in the study were all 29 employees with the census sampling technique. Data analysis used descriptive statistics with the Rating Scale measurement scale. The results of the study in the factors that affect the performance of services at Dumai Timur District office are categorized as quite good, with an average of 2236 (65.90\%).
\end{abstract}




\section{PENDAHULUAN}

Terwujudnya pelayanan publik yang berkualitas oleh pemerintah adalah dengan membenahi standar pelayanan dengan cepat, tepat, memuaskan, transparan dan tanpa diskriminasi (Suherman et al., 2020). Pengorganisasian yang baik dengan perencanaan pelayanan yang optimal dengan memanfaatkan sumber daya yang ada tentunya akan menghasilkan kinerja pegawai yang baik (Wuri, 202I). Hal ini penting, sebab dengan baiknya kinerja pegawai, maka kontribusi yang pegawai lakukan dalam menjalankan tugas dan tanggung jawabnya pasti akan baik.

Undang-Undang Nomor 25 Tahun 2009 tentang pelayanan publik di Indonesia serta Peraturan Pemerintah nomor 96 Tahun 2012 tentang peraturan pelayanan publik telah mengatur pemberian pelayanan yang sesuai dengan tuntutan masyarakat Indonesia (Afrizal et al., 2019). Keberhasilan dari pelayanan tentunya diperlukan sebuah komitmen dalam pelaksanaannya (Afrizal, 2020). Pelayanan adalah pendekatan yang penting untuk melayani masyarakat secara berkualitas dan menjadi penggerak dalam kegiatannya (Ibrahim, 2019). Sedangkan pelayanan publik menurut Sinambela (2017) adalah sebuah kegiatan pemberian pelayanan dari pemerintah ke masyarakatnya secara keseluruhan. Sedangkan menurut (Rahmadana et al., 2020) mengatakan bahwa pelayanan publik merupakan sebuah pembelian layanan yang memiliki kepentingan organisasi sesuai dengan aturan yang telah dibuat. Dwiyanto (202I) mengatakan pelayanan publik berupa kegiatan pelayanan yang dilaksanakan oleh pihak penyedia pelayanan dalam memenuhi keinginan dan kebutuhan maasyarakat yang sesuai dengan peraturan perundang yang berlaku.

Dalam penelitian pelayanan publik, pendapat yang terkenal dan menjadi ukuran dalam pelayanan adalah menurut Fitzsimmons dalam Afrizal et al ( 2019) menjelaskan bahwa dalam melihat pelayanan publik terdapat 5 elemen yaitu antara lain (I) Reability yaitu yang tepat dan benar, (2) Tangibles yaitu SDM yang cukup, (3) Responsif Rasa melayani dengan cepat dan tepat, (4) Assurance yaitu bagaimana etika yang dijalankan serta yang ke yaitu (5) Empati bagaimana memahami keinginan masyarakat sebagai penerima pelayanan.

Pentingnya peran dari pegawai yang berkomitmen dalam menjalankan pelayanan sesuai dengan yang diharapkan. Pegawai dituntut untuk meningkatkan kinerjanya dengan mengembangkan semangat bekerja dan tanggung jawab dalam memberikan pelayanan publik. Kemampuan dan keahlian dalam menjalankan tugas pelayanan tentunya diharapkan agar tujuan dari dibentuknya organisasi publik menjadi penting dalam aktifitas pelayanan publik (Prasetyo et al., 2020).

Disamping itu, pemerintah sebagai penyedia layanan juga dituntut untuk memberikan kepuasan kepada masyarakat dalam bidang pelayanan. Seperti halnya pada Kantor Camat Dumai Timur, dalam menjalankan aktifitasnya memberikan pelayanan yang adil dan merata terhadap masyarakat. Diera transparansi saat ini, kinerja pegawai dibirokrasi publik menjadi pusat perhatian masyarakat dimana saat ini isu yang terjadi dan melakat di masyarakat adalah buruknya pelayanan (Dwiyanto, 2021). Menurut Guritno dan Waridin dalam Ichsan et al (2020) mengatakan kinerja adalah perbandingan antara hasil kerja yang telah di capai dan standar kerja yang ada. Sedangkan Hakim (2010: 97) mengatakan bahwa kinerja adalah sebagai hasil kerja individu yang dalam suatu organisasi pada suatu periode waktu tertentu. Hal yang sama juga disampaikan oleh Simanjuntak dalam (Juarisman et al., 2020) mengatakan bahwa kinerja adalah sebuah tingkatan hasil capaian dari sebuah kegiatan tertentu. Sedangkan menurut Mahmudi dalam (Setiawati, 2020) mengatakan bahwa salah satu upaya untuk melihat kinerja pemerintahan yang bersih dan efisien, tanggap, dan akuntabel dapat dilihat dari (I). penampilan dalam melayani masyarakat, (2) disiplin dan ketaatan terhadap aturan, (3) Kemauan dan Kemampuan untuk mau 
belajar, (4) menjalin hubungan yang baik, (5) memiliki motivasi diri, (6) Cermat, teliti, terampil, cepat dan berkualitas, (7) mampu beradaptasi dan bekerja sama, (8) mampu mengatasi mengatasi masalah, berani dan arif, (9) mampu berkomunikasi, (10) mampu memimpin dan mengorganisasi. Sedangkan Ratminto \& Winarsih (20I3) mengatakan adal3 faktor yang mempengaruhi kinerja pelayanan yang meliputi : (I) strategi pelayanan, (2) petugas atau pejabat yang berorientasi pada klien, (3) sistem pelayanan yang berorientasi pada klien, (4) komitmen manajemen, (5) perumusan tujuan organisasi, (6) standarisasi tugas, (7) kepaduan tim, (8) kesesuaian orang-pekerjaan, (9) kesesuaian teknologi-pekerjaan, (I0) realitas kontrol, (II) kejelasan peran, (I2) konflik peran dan (13) tingkatan manajemen.

Kantor Camat Dumai Timur Kota Dumai berdasarkan Peraturan Walikota Dumai No. 72 Tahun 2016 tentang kedudukan, susunan organisasi, tugas dan fungsi serta tata kerja kecamatan dan kelurahan memberikan pelayanan kepada masyarakatnya. Adapun jenis pelayanan yang diberikan adalah:

Tabel I. Jenis Pelayanan

\begin{tabular}{cl}
\hline No & \multicolumn{1}{c}{ Produk Pelayanan } \\
\hline I. & Pengurusan Keterangan Surat Pernyataan Kuasa Ahli Waris \\
2. & Surat Keterangan Domisili \\
3. & Pengurusan Dispensasi Pernikahan \\
4. & Surat Keterangan Pindah \\
5. & Surat pengantar Kartu Keluarga (KK) \\
6. & Pengurusan izin pemakaian tempat \\
7. & Surat Rekomendasi tempat lbadah dan TPA \\
8. & Pengurusan Surat Keterangan Ganti Rugi (SKGR) \\
9. & Surat Keterangan Tidak Mampu (SKTM) \\
I0. & Penerbitan Surat izin usaha \\
II. & Surat Rekomendasi IMB tower \\
I2. & Surat Pengantar Keterangan Catatan Kepolisian (SKCK) \\
I3. & Surat Pengantar Akte Kelahiran
\end{tabular}

Sumber : Kantor Camat Dumai Timur, 2020

Namun, dalam pelaksanaan pemberian pelayanan masih adanya keluhan dari sebagian masyarakat pada saat proses pengurusan, pelayanan yang diterima dirasa masih belum memuaskan. Keluhan seperti prosedur berbelit-belit, tidak adanya kepastian waktu pelayanan, sikap petugas yang kurang ramah dan responsif dalam menyelesaikan permasalahan pelayanan sehingga beberapa masyarakat merasakan tidak terlayani dengan baik.

Alur pelayanan yang dilakukan di Kantor Camat Dumai Timur sebagai berikut:

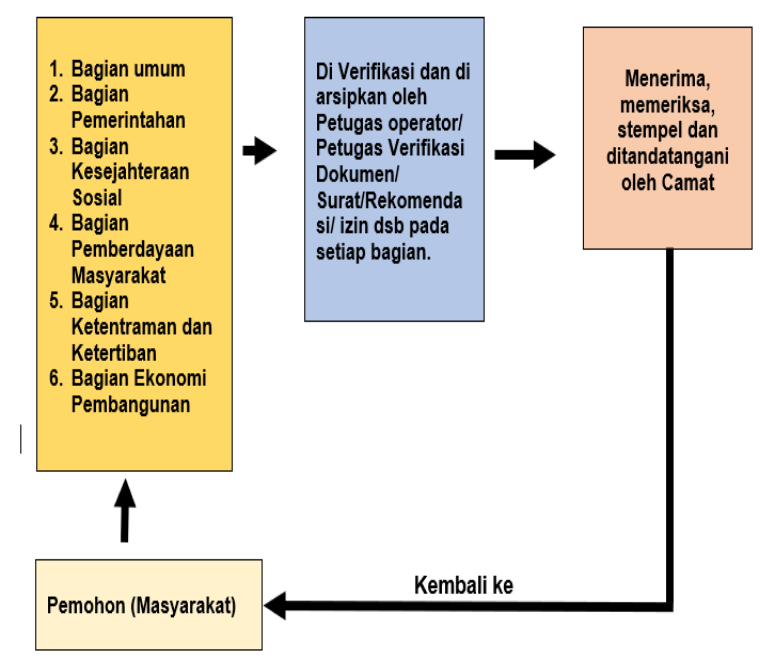

Gambar I. Alur Pelayanan

Hingga saat ini, keterlibatan pegawai Kantor Camat Dumai Timur dalam upaya melayani masyarakat telah dilakukan dengan rasa tanggung jawab sebagai abdi masyarakat untuk melayani kepentingan masyarakat agar pelayanan yang diberi mendapatkan cerminan yang positif bagi masyarakatnya. Oleh karena itu, penelitian ini akan melihat faktor apa saja yang mempengaruhi kinerja pelayanan di Kantor Camat Dumai Timur Kota Dumai.

\section{METODOLOGI}

Lokasi penelitian adalah Kantor Camat Dumai Timur. Penelitian dilakukan dengan menggunakan pendekatan Kuantitatif dengan metode survei, Menetapkan responden yaitu seluruh pegawai dengan total seluruhnya 29 responden dengan tehnik pengambilan sampel menggunakan sensus sampling (Jonathan, 2006). Data primer diperoleh dengan menyebarkan angket/kuesioner dan data skunder didapat dari lokasi penelitian. Data yang terkumpul 
dianalisa dengan cara statistik deskriptif dengan menggunakan skala pengukuran Rating Scale.

\section{HASIL DAN PEMBAHASAN}

\section{Strategi Pelayanan}

Strategi pelayanan adalah suatu langkah atau cara yang dibuat dan dilaksanakan pegawai Kantor Camat Dumai Timur dalam memberikan pelayanan publik sehingga masyarakat terlayani dengan baik. Strategi pelayanan dapat dilihat dari terdapatnya pegawai yang melakukan pelayanan sesuai dengan prosedur, terdapatnya pegawai yang mampu memahami kebutuhan masyarakat dan terdapatnya pegawai yang mampu memberikan solusi dalam permasalahan pelayanan.

\section{Petugas yang berorientasi pada masyarakat.}

Yang dimaksud dengan petugas yang berorientasi pada masyarakat adalah pegawai Kantor Camat Dumai Timur dalam melayani masyarakat mengutamakan kepentingan masyarakat yang dilayani sehingga masyarakat mendapat kepuasan terhadap pelayanan yang dilakukan. Pegawai yang berorientasi pada klien dilihat dari terdapatnya pegawai yang mengutamakan kepentingan masyarakat dalam pelayanan dan pegawai yang mampu memberikan kepuasan kepada masyarakat serta pegawai yang tidak diskriminatif dalam pelayanan.

\section{Sistem pelayanan yang berorientasi pada} masyarakat

Yang dimaksud dengan sistem pelayanan yang berorientasi pada masyarakat adalah mekanisme pelayanan pada Kantor Camat Dumai Timur bertujuan untuk memberikan kepuasan dalam pelayanan. Sistem pelayanan yang berorientasi pada klien dilihat dari terdapatnya prosedur pada setiap bagian pelayanan, terdapatnya persyaratan lengkap dari penerima pelayanan dan adanya pusat informasi pelayanan yang mempermudah masyarakat.

\section{Komitmen manajemen}

Komitmen manajemen merupakan kemampuan Kantor Camat Dumai Timur melakukan pelayanan sesuai dengan aturan yang telah ditetapkan dan dilaksanakan seluruh pegawai yang telah ditetapkan. Komitmen manajemen dilihat dari terdapatnya pegawai yang memberikan pelayanan dengan tepat waktu, adanya kesepakatan bersama dalam menetapkan suatu keputusan serta pelaksanaan kerja sesuai dengan waktu yang telah ditentukan.

\section{Perumusan tujuan organisasi.}

Perumusan tujuan organisasi adalah dibuat rumusan kerja sebagai bentuk visi dan misi Kantor Camat Dumai Timur dalam menjalankan pekerjaan agar mencapai tujuan yang di inginkan. Perumusan tujuan organisasi dilihat dari terdapatnya uraian tentang visi organisasi, adanya program kerja setiap bidang dan terdapatnya uraian tentang sasaran pencapaian kerja organisasi.

\section{Standarisasi tugas}

Yang dimaksud standarisasi tugas adalah terdapatnya penempatan semua pegawai Kantor Camat Dumai Timur di unit kerja/bagian dan diberikan tugas kerja sesuai kemampuan yang dimiliki. Standarisasi tugas dapat dilihat dari terdapatnya tolak ukur pencapaian kerja, pertanggungjawaban kerja pegawai pada masingmasing unit kerja / bagian yang telah diberikan atasan serta terdapatnya pembagian tugas pokok dan fungsi disetiap bidang kerja.

\section{Kepaduan tim}

Kepaduan tim adalah kerjasama yang dilakukan pegawai Kantor Camat Dumai Timur dalam menyelesaikan pekerjaan sehari-hari dan kegiatan lainnya. Kepaduan tim dapat dilihat dari terdapatnya kerjasama antar pegawai dalam menangani masalah, terdapatnya komunikasi yang baik antara sesama pegawai dan terdapatnya hubungan kerja yang baik antar pegawai.

\section{Kesesuaian orang-pekerjaan}

Yang dimaksud dengan kesesuaian orangpekerjaan adalah keahlian yang dimiliki pegawai harus sesuai dengan pekerjaan yang dilakukan dan terdapat 
penyelesaian kerja dengan baik dimasing-masing unit kerja/bagian Kecamatan Dumai Timur dalam pelayanan publik. Kesesuaian orang-pekerjaan akan dilihat dari terdapatnya pegawai yang bekerja sesuai dengan latar belakang pendidikan, terdapatnya pemberian pelatihan untuk meningkatkan keahlian kerja pegawai dan terdapatnya pegawai yang bekerja sesuai dengan keahliannya.

\section{Kesesuaian teknologi-pekerjaan}

Yang dimaksud dengan kesesuaian teknologipekerjaan adalah fasilitas teknologi kerja yang tersedia sesuai dengan bidangnya atau sesuai kebutuhan kerja pegawai Kantor Camat Dumai Timur. Kesesuaian teknologi pekerjaan dapat dilihat dari terdapatnya penggunaan teknologi untuk bidang-bidang yang dibutuhkan, terdapatnya pegawai mampu mengunakan teknologi tersebut serta, adanya fasilitas yang lengkap pada setiap bidang.

\section{Realitas control}

Realitas control merupakan pengarahan yang dilakukan oleh pimpinan di Kantor Camat Dumai Timur tentang mekanisme kerja dan dilakukan pengawasan bagi semua pegawai dalam menjalankan kerja. Realitas control dapat dilihat dari terdapatnya pengarahan kerja yang diberikan oleh atasan, terdapatnya pengawasan pada pegawai sewaktu jam kerja, dan terdapatnya pemberian sangsi.

\section{Kejelasan peran}

Yang dimaksud kejelasan peran adalah penempatan pegawai Kantor Camat Dumai Timur masing-masing unit kerja/bagian dalam menjalankan tugas yang diberikan sesuai dengan tuntutan dari atasan. Kejelasan peran akan dilihat dari terdapatnya pembagian kerja secara spesifik untuk setiap pegawai, adanya penjelasan kerja yang ditunjuk oleh atasan kepada bawahan serta erdapatnya aturan tentang pembatasan ruang lingkup pekerjaan.

\section{Konflik peran}

Yang dimaksud dengan konflik peran adalah timbulnya rasa kecemburuan sesama pegawai Kantor
Camat Dumai Timur dalam menjalankan kerja dimana kecemburuan tersebut mengakibatkan tidak harmonis sehingga terjadi blok/kelompok antar pegawai. Konflik peran akan dapat dilihat melalui dilakukannya kegiatan rapat rutin atasan dengan semua unit kerja / bagian, dilakukannya pembinaan komunikasi dua arah kepada pegawai untuk semua unit kerja / bagian serta terdapatnya solidaritas antar sesama pegawai.

\section{Tingkatan manajemen}

Tingkatan manajemen adalah tingkatan jabatan yang menunjukkan antara atasan, kepala kasi dan bawahan yang mempunyai tugas pokok dan fungsi sesuai aturan yang telah ditetapkan Kantor Camat Dumai Timur. Tingkatan manajemen dapat dilihat dari adanya pembagian tugas berdasarkan tingkatan jabatan dari atasan kepada bawahan berdasarkan aturan yang berlaku, terdapatnya masing-masing tugas pada setiap bagian bidang sesuai dengan jabatan dan terdapatnya pelimpahan wewenang berdasarkan tingkatan struktur organisasi.

Tabel 2. Rekapitulasi Jawaban Responden

\begin{tabular}{clc}
\hline No & \multicolumn{1}{c}{ Indikator } & Skor \\
\hline I. & Strategi pelayanan & 190 \\
2. & Petugas / pejabat yang berorientasi pada klien & 179 \\
3. & Sistem pelayanan yang berorientasi pada klien & 165 \\
4. & Komitmen manajemen & 176 \\
5. & Perumusan tujuan organisasi & 168 \\
6. & Standarisasi tugas & 166 \\
7. & Kepaduan tim & 175 \\
8. & Kesesuaian orang-pekerjaan & 165 \\
9. & Kesesuaian teknologi-pekerjaan & 161 \\
I0. & Realitas kontrol & 165 \\
I1. & Kejelasan peran & 171 \\
12. & Konflik peran & 186 \\
13. & Tingkatan manajemen & 169 \\
\hline & & 2236
\end{tabular}

Sumber : Hasil Penelitian (2020)

Data tersebut terlihat skor jawaban responden sebesar 2236 hal ini dapat dilihat melalui kontinum dibawah ini :

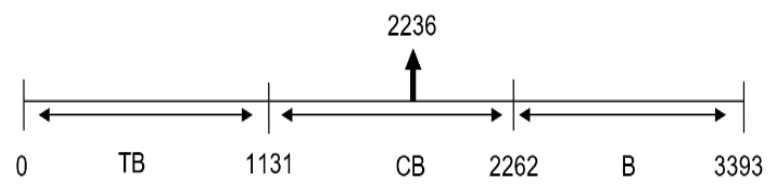


Sedangkan persentasenya adalah:

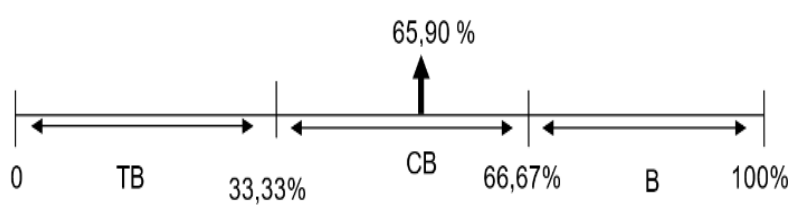

Dari kontinum diatas dapat dilihat tanggapan responden diketegorikan Cukup Baik dengan diperoleh rata-rata $2236(65,90 \%)$.

\section{KESIMPULAN}

Hasil penelitian ditemukan bahwa faktor yang mempengaruhi kinerja pelayanan pada Kantor Camat Dumai Timur Kota Dumai dapat dikategorikan Cukup Baik. Dari jawaban 29 responden Total Skor secara keseluruhan didapat sebanyak 2236 (65,90\%) yang berada pada interval Cukup Baik. Disarankan kepada Camat untuk dapat melakukan pembinaan/pelatihan bagi semua pegawai dan diharapkan pegawai mampu melaksanakan tugasnya sesuai dengan ketetapan prosedur yang telah ditetapkan dan meningkatkan pelayanan kearah yang lebih baik, cepat, tanggap, ramah serta kedepannya dapat meningkatkan pusat informasi pelayanannya kearah e-informasi guna mempermudah masyarakat melakukan pengurusan.

\section{UCAPAN TERIMA KASIH}

Terimakasih yang sebesar-besarnya kepada STIA Lancang Kuning dan Kantor Camat Dumai Timur Kota Dumai yang telah membantu dalam pelaksanaan penelitian

\section{REFERENSI}

Afrizal, D. (2020). E- Government Service Review In Dumai City Indonesia: ( Conceptual Paper ). Jurnal Niara, 13(I), 260-267.

Afrizal, D., Effendi, N., \& Handayani, P. (2019). Upaya Pemberian Pelayanan Publik Di Upt Puskesmas Balai Makam Kabupaten Bengkalis. Jurnal Niara, I2(I), 69-78.
Dwiyanto, A. (202la). Mewujudkan good governance melalui pelayanan publik. UGM PRESS.

Dwiyanto, A. (202/b). Reformasi birokrasi publik di Indonesia. Gajah Mada University Press. https://books.google.co.id/books?hl=id\&lr=\&id=v TMXEAAAQBAJ\&oi=fnd\&pg=PAI\&dq=burukny a+pelayanan+yang+diberikan+oleh+birokrasi+pu blik\&ots=vP2FGUKuo2\&sig=PTzgFhs_MW9fqc OHCp4MYsX8dC4\&redir_esc $=y \# v=o n e p a g e \& q$ =buruknya pelayanan yang diberikan oleh birokrasi pub

Ibrahim, H. A. (2019). Teori dan konsep pelayanan publik serta implementasinya.

Ichsan, R. N., Surianta, E., \& Nasution, L. (2020). Pengaruh Disiplin Kerja Terhadap Kinerja Pegawai Negeri Sipil (Pns) Di Lingkungan Ajudan Jenderal Daerah Militer (Ajendam) - I Bukitbarisan Medan. Jurnal Darma Agung, 28(2), 187. https://doi.org// 0.46930/ojsuda.v28i2.625

Jonathan, S. (2006). Metode Penelitian Kuantitatif \& Kualitatif (Edisi Pert). Graha IImu.

Juarisman, R., Tua, H., \& Yusri, A. (2020). Evaluasi kinerja pelayanan Publik. JIANA Jurnal Ilmu Administrasi Negara), 16(I), 163-173.

Prasetyo, R., Normajatun, \& Ilmu, F. (2020). Penyelenggaraan Pelayanan Publik Di Kecamatan Kusan Hulu Kabupaten Tanah Bumbu. In Universitas Islam Kalimantan.

Rahmadana, M. F., Mawati, A. T., Siagian, N., Peranginangin, M. A., Refelino, J., Tojiri, M. Y., Siagian, V., Nugraha, N. A., Manullang, S. O., \& Silalahi, M. (2020). Pelayanan Publik. Yayasan Kita Menulis.

Ratminto, \& Winarsih, A. S. (2013). Manajemen pelayanan. Pustaka Pelajar.

Setiawati, B. (2020). Optimalisasi Kinerja Pelayanan Di Sektor Publik Berbasis Pelaku (Individu). Jurnal PubBis, $\quad 4(1)$, 53-64. http://stiatabalong.ac.id/ojs3/index.php/PubBis/art icle/view/230

Sinambela, L. P. (2017). Reformasi pelayanan publik. Bumi 
Akasara.

Suherman, Afrizal, D., \& Sopyan. (2020). Standar

Pelayanan Puskesmas Selatpanjang Kecamatan

Tebing Tinggi Kabupaten Kepulauan Meranti.

Jurnal Administrasi Publik Dan Bisnis, 2(1), 15-18.

Wuri, J. (202I). Kinerja Pegawai Dalam Pelayanan Publik

Di Era Covid- 9 (Studi Di Kecamatan Langowan

Barat Kabupaten Minahasa). Jurnal Politico, 10(4),

$1-13$. 